\title{
CINÉTICA DA HIDRÓLISE DE ÓLEO VEGETAL POR CATÁLISE ENZIMÁTICA E USO DE ULTRASSOM
}

\author{
A. JACQUES. N ${ }^{1}$, M. C. P. ZENEVICZ ${ }^{1}$ REMONATTO, D. ${ }^{1}$, A. FURIGO Jr${ }^{1}$, D. de \\ OLIVEIRA $^{1}$ e J. V. de OLIVEIRA ${ }^{1}$
}

${ }^{1}$ Universidade Federal de Santa Catarina Departamento de Engenharia Química e Alimentos E-mail para contato: arturjacques@gmail.com

\begin{abstract}
RESUMO - Hidrólise é um processo pelo qual se podem obter diversos produtos de interesse na indústria. A utilização de enzimas para esse processo possibilita a produção de ácidos graxos em temperaturas mais amenas e a obtenção de um produto mais limpo. O ultrassom permite que não seja utilizado emulsificante para a formação de emulsões e fornece a agitação necessária para que a reação ocorra. As reações foram realizadas com agitação de $300 \mathrm{rpm}$ em um frasco de vidro com potência ultrassônica de $132 \mathrm{~W}$, o uso de $10 \%$ de enzima Lipozyme TL IM (em relação a massa do substrato) e uma razão de óleo:água de $1: 20$ a $40{ }^{\circ} \mathrm{C}$, variando somente o tempo de cada reação. Observou-se que após que o tempo de $2 \mathrm{~h}$ o meio reacional se mantinha estável, e que a enzima poderia ser reutilizada com $50 \%$ de eficiência.
\end{abstract}

\section{INTRODUÇÃO}

A utilização de enzimas para catalisar as reações tem se mostrado um grande avanço na química contemporânea, podendo reagir em temperaturas amenas sendo especificas e extremamente eficientes. $\mathrm{O}$ uso da enzima do tipo lípase possibilita a formação de um produto biodegradável com uma menor formação de resíduos (Castro et al., 2004). Lípases são enzimas capazes de catalisar reações com lipídios (óleos) com diversos substratos sendo lipídios e água (hidrólise), ácido carboxílico e álcool (esterificação), éster e ácido carboxílico (acidólise), óleo vegetal ou gordura animal e álcool (transesterificação) (Carvalho et al., 2003).

O uso de ultrassom fornece parte da energia necessária para que a reação ocorra e promove a formação de uma emulsão, sem uso de agitação mecânica, moinhos coloidais, homogeneizadores ou alta pressão. Porém na reação que foi realizadas utilizou-se agitação mecânica a $300 \mathrm{rpm}$ para evitar o uso de emulsificantes. A irradiação ultrassônica pode aumentar ou diminuir a vida útil da enzima, dependendo da natureza do biocatalizador e dos substratos envolvidos na reação (Kwiatkowska et al., 2011; Chandralapa et al., 2012).

\section{OBJETIVO}


Este trabalho visa realizar o estudo cinético da hidrólise enzimática de óleo de soja, com o intuito de determinar o melhor tempo de reação para obter o máximo rendimento de ácidos graxos, utilizando ultrassom, em modo batelada. Também estudou a eficiência da enzima para reuso.

\section{MATERIAL E MÉTODOS}

\subsection{Aparato experimental para a hidrólise enzimática}

O aparato experimental para a reação consistiu de um banho de ultrassom (frequência de $37 \mathrm{kHz}$ e potência de $132 \mathrm{~W}$ ) onde foi colocado um recipiente de vidro contendo os reagentes e ao lado foi encaixado um agitador, como demonstrado na Figura 1.

Figura 1- Aparato experimental utilizado para os testes.

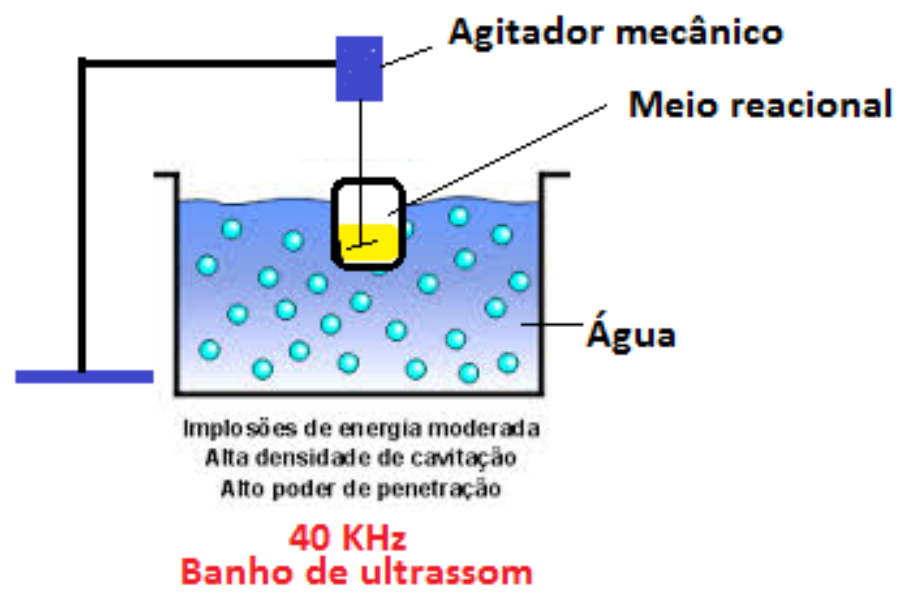

Como substratos foram utilizados óleo de soja (Soya) e água destilada, e o catalisador enzimático Lipozyme TL IM (lipase imobilizada, produzida pela Novozymes ${ }^{\circledR}$, Araucária/PR).

\subsection{Métodos de produção de ácido graxo através do óleo de soja}

O processo foi otimizado na proporção de um molar de óleo de soja para 20 molar de água com uma massa de enzima equivalente a $10 \%$ da massa total do substrato, $137 \mathrm{~W}$ de potência do ultrassom, a $40{ }^{\circ} \mathrm{C}$ e agitação mecânica de $300 \mathrm{rpm}$. Primeiramente adicionou-se em um frasco de vidro a água, o óleo e a enzima e colocou-se no banho com agitação mecânica, esperou-se o tempo designado da cinética destrutiva (onde foram testadas $0,25 \mathrm{~h}$, $0,5 \mathrm{~h}, 1 \mathrm{~h}, 2 \mathrm{~h}, 4 \mathrm{~h}, 6 \mathrm{~h}, 12 \mathrm{~h}, 16 \mathrm{~h}, 20 \mathrm{~h}, 24 \mathrm{~h}$ ). Após o tempo da reação a amostra foi retirada e lavada com iso-propanol, filtrada para recuperação da enzima e o solvente evaporado 
através do rotaevaporador a vácuo à $60^{\circ} \mathrm{C}$. Após foi verificado o teor de acidez das amostras e a atividade da enzimática da enzima antes e depois da reação.

\subsection{Métodos de quantificação}

Determinação da atividade hidrolítica: Para a quantificação da atividade hidrolitíca da enzima utilizou-se a método descrito por Calvacanti et al. (2005). Utilizou-se uma emulsão de azeite de oliva $100 \mathrm{~g} / \mathrm{L}$ e goma arábica $50 \mathrm{~g} / \mathrm{L}$ em tampão fosfato de sódio $0,1 \mathrm{~mol} / \mathrm{L} \mathrm{pH} \mathrm{7,} \mathrm{com} \mathrm{uma}$ agitação de $160 \mathrm{rpm}$ em shaker. Em um erlenmeyer de $250 \mathrm{~mL}$ foi colocado $20 \mathrm{~mL}$ da emulsão formada e $0,1 \mathrm{~g}$ de enzima após $20 \mathrm{~min}$ a 40 ou $65^{\circ} \mathrm{C}$, após o período determinado a reação foi interrompida, e a reação paralisada pela adição de $20 \mathrm{~mL}$ de uma solução de acetona/etanol $(1: 1 \mathrm{v} / \mathrm{v})$. Após titulou-se com uma solução de $\mathrm{NaOH} 0,05 \mathrm{~mol} / \mathrm{L}$ até $\mathrm{pH} 11$, também foi titulado o branco reacional não reagido, onde utilizou-se os mesmos reagentes que as amostras também tituladas.

Sendo definida uma unidade de atividade de hidrólise (UH) como a quantidade de enzima que libera $1 \mathrm{mmol}(\mathrm{milimol})$ de ácido graxo por minuto nas condições já descritas, o que pode ser determinado utilizando a Equação 1.

$$
A_{H}=\frac{\left(V_{a-} V_{b}\right) * C_{N a O H} * 10^{3}}{t * M_{E}}
$$

Onde:

$\mathbf{A}_{\mathbf{H}}$ : corresponde à atividade hidrolítica $(\mathrm{U} / \mathrm{g})$;

$\mathbf{V}_{\mathrm{a}}$ e $\mathbf{V}_{\mathbf{b}}$ : $\mathrm{V}_{\mathrm{b}}$ corresponde ao volume de $\mathrm{NaOH}$ utilizado para titular a amostra após a reação e $\mathrm{V}_{\mathrm{a}}$ ao volume gasto para titular a amostra antes da reação;

$\mathbf{C}_{\mathrm{NaOH}}$ : é a concentração da solução de $\mathrm{NaOH}(\mathrm{mol} / \mathrm{L})$;

$\mathbf{M}_{\mathbf{E}}$ : equivale a massa de enzima utilizado $(0,1 \mathrm{~g})$;

$\mathbf{t}$ : corresponde ao tempo de reação (min).

Quantificação do teor de ácidos graxos livres: A quantificação dos ácidos graxos livres foi realizada através do método IUPAC 2.201 que consiste em dissolver aproximadamente $3 \mathrm{~g}$ da sua amostra em $50 \mathrm{~mL}$ de uma solução etanol e éter $1: 1(\mathrm{v} / \mathrm{v})$. Coloca-se 3 gotas de fenolftaleína e titula-se com $\mathrm{KOH} 0,1 \mathrm{~mol} / \mathrm{L}$ estando o recipiente da mistura sobre agitação constante, quando ocorre a mudança de coloração interrompe-se o fluxo de $\mathrm{KOH}$ imediatamente e verifica-se o volume do mesmo que foi utilizado. A acidez é calculada usando a Equação 2:

$$
C_{A G L}=\frac{V * C_{K O H} * M M_{A G L}}{10 * M_{a}}
$$

Onde: 
$\mathbf{C}_{\mathbf{A G L}}$ : corresponde ao teor de ácido graxo livre em porcentagem mássica $(\mathrm{m} / \mathrm{m}, \%)$;

V: é o volume da solução de $\mathrm{KOH}$ utilizado na titulação $(\mathrm{mL})$;

$\mathbf{C}_{\mathbf{K O H}}$ : significa à concentração da solução de $\mathrm{KOH}(\mathrm{mol} / \mathrm{L})$;

$\mathbf{M M}_{\mathbf{A G L}}$ : corresponde à massa molecular médio dos ácidos graxos presentes no óleo $(282 \mathrm{~g} / \mathrm{mol})$;

Ma: corresponde amassa da amostra $(\mathrm{g})$.

\section{RESULTADOS E DISCUSSÕES}

\subsection{Hidrólise enzimática}

Foram realizados experimentos variando o tempo de $0,25 \mathrm{~h}$ até 24 horas, com razão óleo:água de 1:20 e concentração enzimática de $10 \%(\mathrm{~m} / \mathrm{m}$ em relação ao substrato) em um reator de vidro, com agitação de $300 \mathrm{rpm}$ e $137 \mathrm{~W}$ de potência do ultrassom a uma tempetatura de $40{ }^{\circ} \mathrm{C}$, em modo batelada.

Figura 2- Hidrólise de óleo de soja catalisada por lipase Lipozyme TL IM com emprego do ultrassom, apresentado em teor de acidez em função do tempo de reação. Condições experimentais: razão molar óleo/água $1: 9,40{ }^{\circ} \mathrm{C}, 10 \%(\mathrm{~m} / \mathrm{m})$ de enzima (baseado no total do substrato), $137 \mathrm{~W}$ de potência do ultrassom e $300 \mathrm{rpm}$.

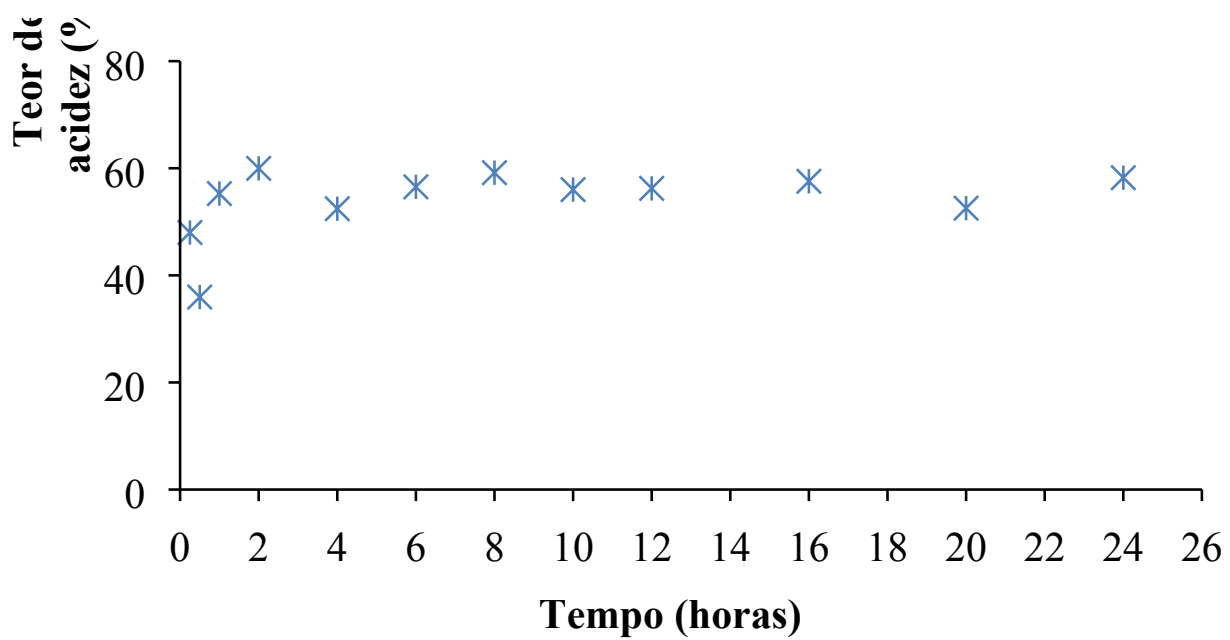

Como pode-se observar na Figura 2, onde é apresentada a cinética de hidrólise enzimática de óleo de soja, verificou-se que a partir de $2 \mathrm{~h}$ a reação se mantém com relativa estábilidade com algumas flutuações pois se trata de uma cinética destrutiva, e cada ponto é uma reação diferente causando flutuações nos dados obtidos. Porém mesmo com essa flutuações é possivel notar visualmente quando a reação está finalizada pois forma-se uma mistura branca e viscosa no meio reacional, isso acontece mais ou menos após um perido de 1,5 h, deixa-se um tempo de reação a mais para garantir que não haverá mais conversão. Há uma diferença na velocidade da reação dependendo de como o agitador está colocado na amostra, mexendo o frasco durante a reação de forma a remover a enzima que está fixada nos 
cantos também faz com que se obtenha maior rendimento. Isso causa uma leve diferença entre no indice de ácidez dos pontos.

Porém podemos observar que após 2 horas os pontos ficam flutuando entre $50 \%$ e $60 \%$, acredita-se que há influencia no rendimento da reação por causa da posição em que o agitador está colocado e a posição do ultrassom, não só do tempo . Sendo assim o tempo de 2 horas é o nescessário para que a amostra atinja o valor máximo.

Cavalheiro (2013), utilizando uma proporção de 21:1água:óleo de canola $(\mathrm{m} / \mathrm{m})$ e $12,5 \%$ (em relação à massa de óleo) de uma combinação das enzimas Lipozyme RM IM e Lipozyme TL IM em uma proporção de 4:1 respectivamente a uma temperatura de $40{ }^{\circ} \mathrm{C}$ sem o uso de ultrassom obteve uma conversão de $58,51 \%$ após $5 \mathrm{~h}$ de reação.

\subsection{Atividade enzimática}

Vericou-se a atividade enzimática em U/g da Lipozyme TL IM antes da enzima ser adicionada no meio reacional e após o tempo de reação. Na tabela 1 está apresentada os resultados da atividade inicial e final da lipase e suas respectivas atividades residuais.

Figura 1-Atividade enzimática da lipase Lipozyme TL IM antes da reação de hidrólise e após a reação

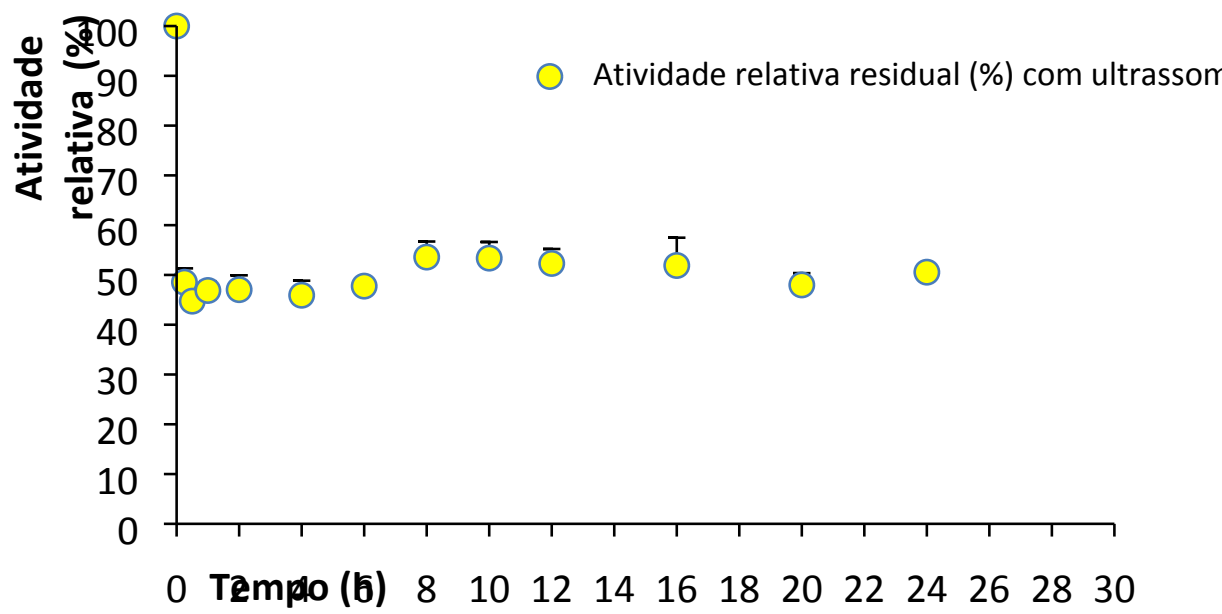

Podemos observar na tabela 1 que a atividade residual da enzima foi cerca de $50 \%$ em todas as amostras, sugerindo que a perda de atividade não está ligada ao quanto de trigliacilglicerol ela converteu em ácido graxo e sim ao choque de $\mathrm{pH}$ com o meio, pois mediu-se o pH inicial da reação na presença da água e o óleo e constatou-se um pH de 3,9, este relativamente ácido para a enzima. Segundo Dong; Wong; Chang (2010) as enzimas 
sofrem grande influência do $\mathrm{pH}$, sendo que biocatalizadores, em $\mathrm{pH}$ extremos podem perder totalmente a atividade. Porém, com váriações mais brandas pode haver uma desnaturação parcial da enzima acarretando uma diminuição na atividade da enzimática. Essa diminuição não é considerada tão significativa (cerca de 50\%), e a enzima está imobilizada o que permite que, posteriormente, ela seja recuperada. A reutilizada na reação, propicia o maior aproveitamento do catalisador e ganho financeiro.

\section{CONCLUSÃO}

Esse trabalho teve como objetivo a realização de uma cinética enzimática da hidrólise do óleo se soja e uso de ultrassom. Afim de encontrar o melhor tempo para que a reação obtenha um rendimento máximo. Realizou-se 12 testes variando o tempo de reação e mantendo constante a agitação de $300 \mathrm{rpm}$, a enzima Lipozyme TL IM, a proporção óleo: água de 1:20, o ultrassom a $137 \mathrm{~W}$ de potencia e $10 \%$ de enzima $(\mathrm{m} / \mathrm{m}$ em relação ao substrato) e a temperatura de $40{ }^{\circ} \mathrm{C}$.

Verificou-se que a posição do agitador influenciou na velocidade da reção, dessa forma o melhor tempo de reação podemos concluir que seja o de $2 \mathrm{~h}$, para que tenha menor gasto de energia e ainda conserve a conversão. Constatou-se também que a atividade ezimática após a reação era em torno de $50 \%$ em relação a inicial e permanecia nessa quantidade independente de o quanto reagiu e do tempo decorrido que permite o reuso da mesma para reações posteriores.

\section{REFERÊNCIAS}

CARVALHO, P. O.; CAMPOS P. R. B, NOFFS, M. A, OLIVEIRA, J. G. SHIMIZU, M. T. SILVA, D. M. Aplicação de lipases microbianas na obtenção de concentrados de ácidos graxos poliinsaturados. Química Nova, v. 26, p. 75-80, 2003.

CASTRO, H. F.; MENDES, A. A.; SANTOS, J. C.; AGUIAR, C. L. Modificação de óleos e gorduras por biotransformação. Química Nova, v.27, p.146-156, 2004.

CAVAlCANTI-OLIVEIRA, E. D'A.; SILVA, P. R. DA; RAMOS, A. P.; ARANDA, D. A. G.; FREIRE, D. M. G. Study of Soybean Oil Hydrolysis Catalyzed by Thermomyces lanuginosus Lipase and Its Application to Biodiesel Production via Hydroesterification Enzyme Research Article ID 618692, 8 doi:10.4061/2011/618692. v. 2011, 2011.

CAVAlHEIRO, J. C. Hidrólise de óleo de canola catalisada por misturas de lipases imobilizadas, 2013.

CHANDRAPALA, J.; OLIVER, C.; KENTISH, S.; ASHOKKUMAR, M. Ultrasonics in food processing, Ultrason. Sonochem. v.19, p.975-983, 2012. 
DONG, H.P, WANG, Y.J., ZHENG, Y.G. Enantioselective hydrolysis of diethyl 3hydroxyglutarate to ethyl (S)-3hydroxyglutarate by immobilized Candida antarctica lipase B. Journal of Molecular Biocatalysis B, Enzymatic, v.66, p 90-94, 2010

KWIATKOWSKA B.; BENNETT, J.; AKUNNA, J.; WALKER, G. M.; BREMNER D. H., Stimulation of bioprocesses by ultrasound. Biotechnology Advances, v.29, p.768-780, 2011. 